Research Article

\title{
Ergonomic Study and Design of the Pulpit of a Wire Rod Mill at an Integrated Steel Plant
}

\author{
Chandra P. Dewangan and Arun K. Singh \\ Department of Mechanical Engineering, Visvesvaraya National Institute of Technology, Nagpur 440010, India \\ Correspondence should be addressed to Arun K. Singh; aksinghb@gmail.com
}

Received 26 September 2014; Revised 17 December 2014; Accepted 19 December 2014

Academic Editor: Enrico Cagno

Copyright (c) 2015 C. P. Dewangan and A. K. Singh. This is an open access article distributed under the Creative Commons Attribution License, which permits unrestricted use, distribution, and reproduction in any medium, provided the original work is properly cited.

\begin{abstract}
This paper presents ergonomic study and design of the pulpit in a wire rod mill at an integrated steel plant. The mill was facing problem of less productivity of workers due to lack of proper work posture and working conditions. The study data were collected from the interview of seven operators involved with the pulpit. Relevant ergonomic tools were used for assessing the survey data for identifying the risk factors involved with these operators. Ergonomically improved pulpit was proposed for reducing the musculoskeletal disorders (MSDs) thereby increasing the productivity of the plant.
\end{abstract}

\section{Introduction}

Ergonomics is the study of workers and their performance at work [1]. In industrial sector, operating different kind of machines is the routine activity performed by the operator. So the workstation should be designed for the workers as per the ergonomic aspects [2]. Ergonomically designed workspace has a great influence in providing a conducive work environment to workers [2]. Ergonomic intervention in workplace or workstation enhances the health of workers as well as their productivity [3]. However, working at an improper workstation may lead to development of different kinds of musculoskeletal disorders (MSDs) amongst the workers as discussed by Duncan [4]. Problems such as occupational diseases, repetitive stress injuries, and occupational overexertion syndrome mostly affect arms and back of workers $[5,6]$. Thus the ergonomic concepts play a vital role in designing workplace and analyzing the tasks [2]. Ergonomically designed workstation provides healthy work environment, safety, and increased efficiency and also reduces work-related musculoskeletal disorders (WMSDs) injuries [7]. Recently, Ouellet and Vézina (2014) have studied MSDs and their prevention on six workers in a meat processing sector [8]. They have recommended the guidelines based on ergonomic concepts for improving the overall performance of the sector [8].
Kuijt-Evers et al. (2003) have discussed the policies of the International Labor Organization (ILO) [9]. The main focus was on the ILO's policies and activities concerning the ergonomics in relation to occupational safety and health [1]. Das and Sengupta (1996) have done ergonomic based design of workplace [2]. These researchers have also reported guidelines based on ergonomics in a systematic manner. Their guidelines provide a conceptual basis for a good workstation design, for example, workstation dimensions and layout [2]. Kuijt-Evers et al. have done the research on the aspects to improve cabin comfort of the wheel loaders and excavators as per the comfort level of operators [9]. A questionnaire was completed by the machine operators to get their opinion about aspects which needed to design a more comfortable vehicle interior [9]. More recently, Denis et al. (2008) have discussed the intervention practices in MSDs prevention [10]. According to them, MSDs affect much of the workforce and remain a major form of occupational ill health [10]. With a view to improving the efficacy of ergonomic interventions, their review article examined preventative actions related with MSDs [3]. McAtamney and Corlett (1993) used only RULA (rapid upper limb assessment) for ergonomic based assessment of body postures [11]. Chiasson et al. (2012), on the other hand, have discussed eight ergonomic tools for evaluating risk factors related with MSDs in a variety of workplace [12]. 


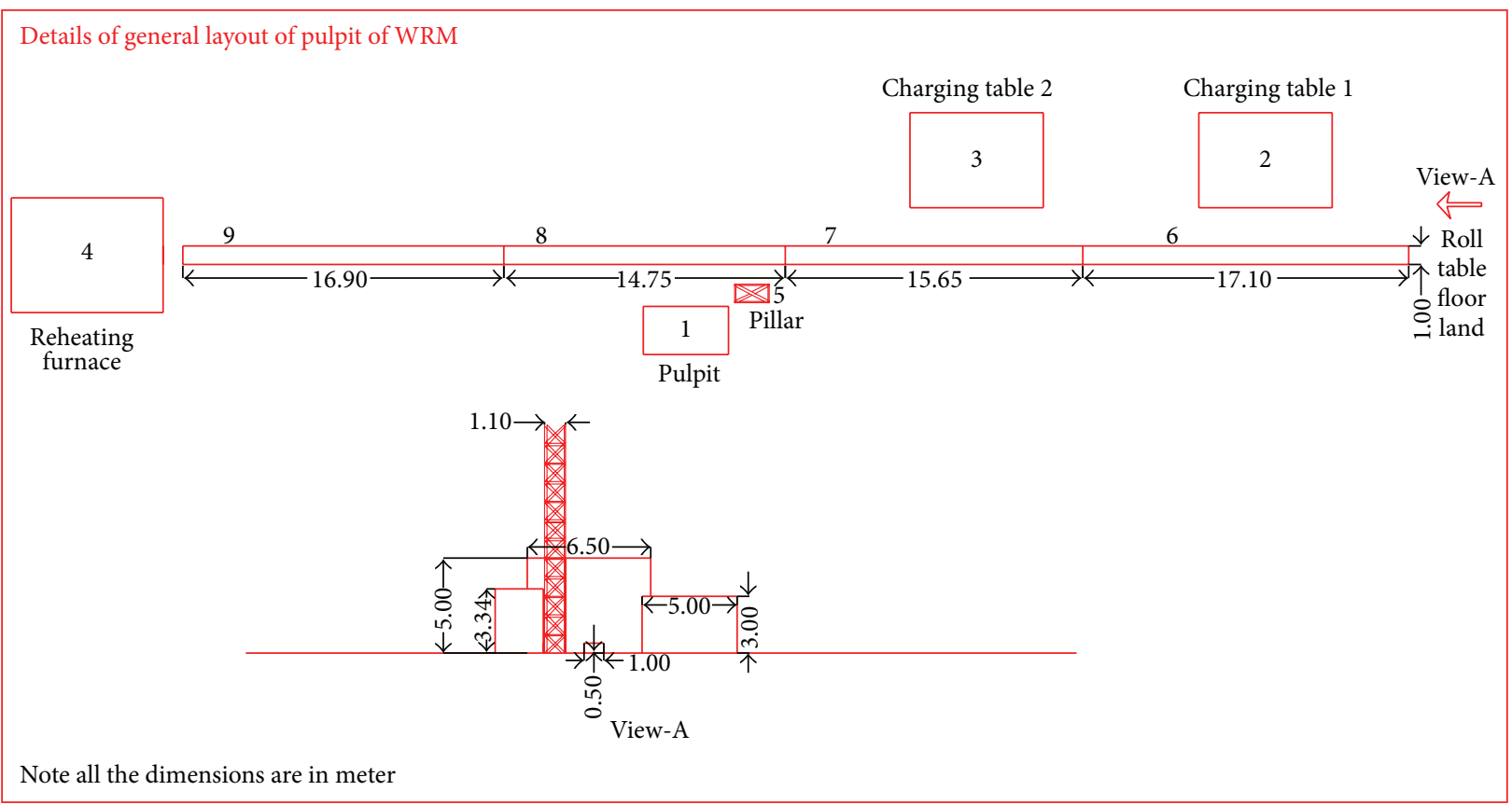
(1) Pulpit
(6) Roll table 1
(2) Charging table 1
(7) Roll table 2
(3) Charging table 2
(8) Roll table 3
(4) Reheating furnace
(9) Roll table 4
(5) Pillar

FIGURE 1: A general layout of the wire rod mill (WRM) which depicts the following: (1) pulpit, (2) charging table 1, (3) charging table 2, (4) reheating furnace, (5) pillar, (6) Roll table 1, (7) Roll table 2, (8) Roll table 3, and (9) Roll table 4.

Pulpit operation is basically a workstation in which a worker has to work in a static posture for long duration. This condition increases unnecessary physical effort on them. Sitting position involving the pulpit alters the normal curvature of the spine and also exerts pressure on the disc [13]. This type of posture also increases the pressure on muscles, ligaments, and other soft tissues of the musculoskeletal system [13]. Consequently overall discomfort and pain in the back, neck, and shoulders are the common symptoms of MSDs observed amongst workers [13]. Hence, it becomes necessary to take corrective steps based on ergonomics to reduce the MSDs of pulpit workers. In addition, it is also to suggest a proper method for work and workstation in which a worker can do the job comfortably without any physical fatigue.

A schematic sketch in Figure 1 shows the details of general layout of a wire rod mill (WRM) at an integrated steel plant. There are four Roll tables as shown in Figure 1. The pulpit is located near the reheating furnace, requiring 180-degree view span of the operator for completion of the required tasks. The pulpit of WRM mainly serves the function of feeding of billets into the reheating furnace by taking the billets from charging tables. As a feeding station, this pulpit is important and critical in view of maintaining the production plan and target of the mill. Considering the importance of the pulpit in the overall operation of the mill, it is decided to conduct its ergonomic analysis.
Figure 2, on the other hand, shows the schematic sketch of the pulpit which is located inside the WRM. The pulpit in Figure 2 is basically a cubicle type control room made of steel structure well insulated from outside placed approximately 10 meters above the ground level (Figure 2). This has dimensions of $4.46 \mathrm{~m}$ length, $2.57 \mathrm{~m}$ width, and $2.34 \mathrm{~m}$ height. The pulpit has one entrance and glasses at the two sides for clear vision of the operation of taking the billets from the charging tables and pushing these billets into the reheating furnace. A video monitor is provided to see the position of billets going to the reheating furnace. A centralized mill monitoring system is also provided to see the signal of operating the control levers. There is a supporting pillar in the right side of the pulpit, which obstructs visibility of operator while transferring the billets from Roll table 2 to Roll table 3 (Figure 1).

1.1. Problem Identification. Motivated from the above literature survey, we have used ErgoFellow software for evaluating and modifying the risk involved with the pulpit of a WRM with recommended design solutions. Seven workers involved with the pulpit operations have participated under their usual working conditions. These workers are between the age groups of 35 and 55 years. To evaluate the actual presence of problems, a detailed ergonomic questionnaire was prepared by considering the information related with MSDs, for instance, working nature, working condition, working 


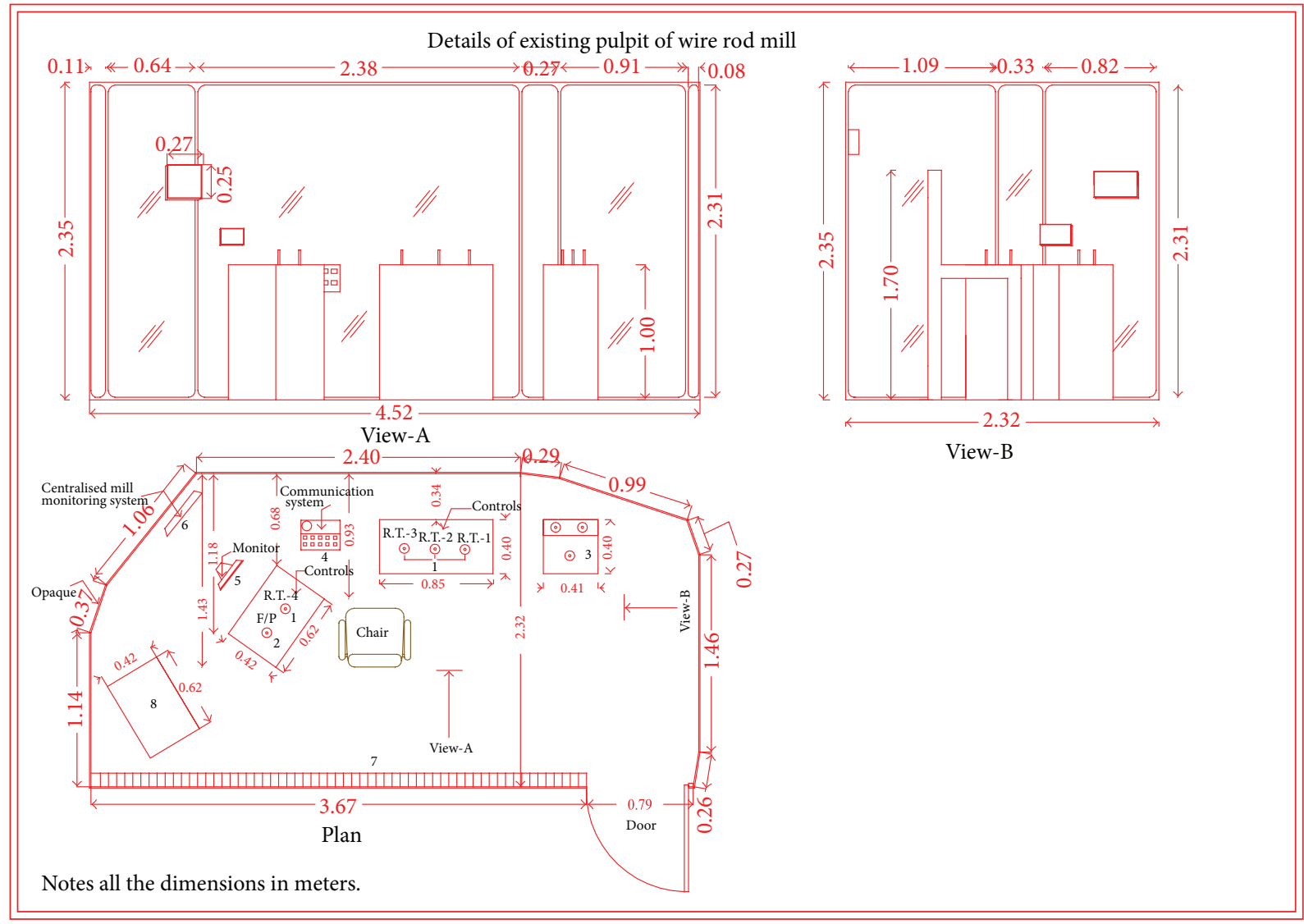
(1) Control levers
(5) Display monitor
(2) Forward pusher
(6) Centralised mill monitoring system
(3) Nonworking control panel
(7) A.C. duct
(4) Communication system
(8) Cooler

Figure 2: A schematic sketch of the pulpit inside the WRM: (1) control levers, (2) forward pusher, (3) nonworking control panel, (4) communication system, (5) display monitor, (6) centralised mill monitoring system, (7) A.C. duct, and (8) cooler.

TABLE 1: Presenting the body posture of upper parts of the bodies of seven operators for RULA analysis.

\begin{tabular}{ccccccccc}
\hline & & \multicolumn{5}{c}{ Postures of the body parts } \\
& Upper arm & Lower arm & Wrist & Wrist twist & Neck & Trunk & Legs & Muscle use and load \\
\hline Number of operators & $20^{\circ}<X<45^{\circ}$ & $60^{\circ}<X<100^{\circ}$ & $15^{\circ}-15^{\circ}$ & - & $20^{\circ}+$ & $20^{\circ}<X<60^{\circ}$ & - & $<2 \mathrm{~kg}$ intermittent load \\
Operator-1 & $35^{\circ}$ & $85^{\circ}$ & $15^{\circ}-15^{\circ}$ & - & $35^{\circ}$ & $45^{\circ}$ & - & $<2 \mathrm{~kg}$ intermittent load \\
Operator-2 & $25^{\circ}$ & $65^{\circ}$ & $15^{\circ}-15^{\circ}$ & - & $25^{\circ}$ & $25^{\circ}$ & - & $<2 \mathrm{~kg}$ intermittent load \\
Operator-3 & $30^{\circ}$ & $70^{\circ}$ & $15^{\circ}-15^{\circ}$ & - & $30^{\circ}$ & $35^{\circ}$ & - & $<2 \mathrm{~kg}$ intermittent load \\
Operator-4 & $30^{\circ}$ & $80^{\circ}$ & $15^{\circ}-15^{\circ}$ & - & $40^{\circ}$ & $40^{\circ}$ & - & $<2 \mathrm{~kg}$ intermittent load \\
Operator-5 & $35^{\circ}$ & $90^{\circ}$ & $15^{\circ}-15^{\circ}$ & - & $35^{\circ}$ & $30^{\circ}$ & - & $<2 \mathrm{~kg}$ intermittent load \\
Operator-6 & $40^{\circ}$ & $75^{\circ}$ & $15^{\circ}-15^{\circ}$ & - & $25^{\circ}$ & $45^{\circ}$ & - & $<2 \mathrm{~kg}$ intermittent load \\
Operator-7 & $45^{\circ}$ & $95^{\circ}$ & $15^{\circ}-15^{\circ}$ & - & $40^{\circ}$ & $55^{\circ}$ & - & $<2 \mathrm{~kg} \mathrm{intermittent} \mathrm{load}$ \\
\hline
\end{tabular}

environment, compatibility, and working hours [13]. A survey of these seven workers was carried out via interview which was based on ergonomic questionnaire. Table 1 contains the survey data related with the postures of the upper parts of the bodies of seven workers. Table 2, in contrast, shows the angle movement of the entire bodies of seven workers.

In addition to Tables 1 and 2, ergonomic questionnaire was also used to analyse the MSDs likely to develop among operators due to present working conditions. For instance, 
TABLE 2: Presenting the angle movement of different parts of the entire bodies of seven operators for REBA analysis.

\begin{tabular}{|c|c|c|c|c|c|c|c|c|}
\hline & \multicolumn{8}{|c|}{ Postures of the body parts } \\
\hline & \multicolumn{3}{|c|}{ Neck, trunk, and legs } & \multirow{2}{*}{ Load } & \multicolumn{3}{|c|}{ Upper arm, lower arm, and wrist } & \multirow{2}{*}{ Activity } \\
\hline & Neck & Trunk & Legs & & Upper arm & Lower arm & Wrist & \\
\hline Number of operators & $>20^{\circ}$ & $0^{\circ}<X<20^{\circ}$ & $>60^{\circ}$ & $<5 \mathrm{~kg}$ & $45^{\circ}<90^{\circ}$ & $60^{\circ}<100^{\circ}$ & $>15^{\circ}$ & Repeated \\
\hline Operator-1 & $30^{\circ}$ & $15^{\circ}$ & $80^{\circ}$ & $<5 \mathrm{~kg}$ & $75^{\circ}$ & $75^{\circ}$ & $30^{\circ}$ & Repeated \\
\hline Operator-2 & $25^{\circ}$ & $5^{\circ}$ & $70^{\circ}$ & $<5 \mathrm{~kg}$ & $50^{\circ}$ & $65^{\circ}$ & $20^{\circ}$ & Repeated \\
\hline Operator-3 & $35^{\circ}$ & $10^{\circ}$ & $75^{\circ}$ & $<5 \mathrm{~kg}$ & $55^{\circ}$ & $95^{\circ}$ & $30^{\circ}$ & Repeated \\
\hline Operator-4 & $45^{\circ}$ & $10^{\circ}$ & $80^{\circ}$ & $<5 \mathrm{~kg}$ & $60^{\circ}$ & $85^{\circ}$ & $25^{\circ}$ & Repeated \\
\hline Operator-5 & $30^{\circ}$ & $15^{\circ}$ & $90^{\circ}$ & $<5 \mathrm{~kg}$ & $75^{\circ}$ & $75^{\circ}$ & $30^{\circ}$ & Repeated \\
\hline Operator-6 & $35^{\circ}$ & $10^{\circ}$ & $75^{\circ}$ & $<5 \mathrm{~kg}$ & $80^{\circ}$ & $75^{\circ}$ & $35^{\circ}$ & Repeated \\
\hline Operator-7 & $45^{\circ}$ & $5^{\circ}$ & $80^{\circ}$ & $<5 \mathrm{~kg}$ & $60^{\circ}$ & $70^{\circ}$ & $25^{\circ}$ & Repeated \\
\hline
\end{tabular}

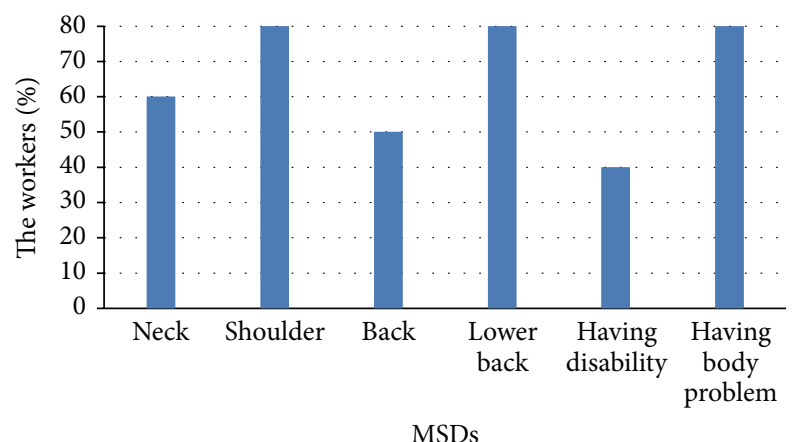

FIGURE 3: Showing workers suffering from MSD problems in their body parts.

bar chart in Figure 3 reveals that all seven workers experience some type of MSDs.

Figure 4, on the other hand, shows the bar chart related with the satisfaction level of all seven operators working at the pulpit. It is seen that workers are not satisfied with the present working conditions.

In addition to survey data related with seven workers, other problems were also observed in the existing pulpit. These problems are listed as follows.

(1) The height of the sitting chair was too high and not comfortable for continuous operation up to $8 \mathrm{hrs}$.

(2) In the existing design of control panel desk, the working span of the operator was very wide due to which the operators experience difficulty in reaching the levers.

(3) Out of the seven control levers, only five levers were functional. The other two levers were nonfunctional. The working levers were also having wide area of work span. Nonworking levers were occupying unnecessary area.

(4) The visibility towards charging table's side as well as reheating furnace side was poor from the pulpit.

(5) There was nonvisibility of billet movement in certain section of Roll tables 2 and 3 due to a supporting pillar.

(6) The existing air cooling system is found to be ineffective.

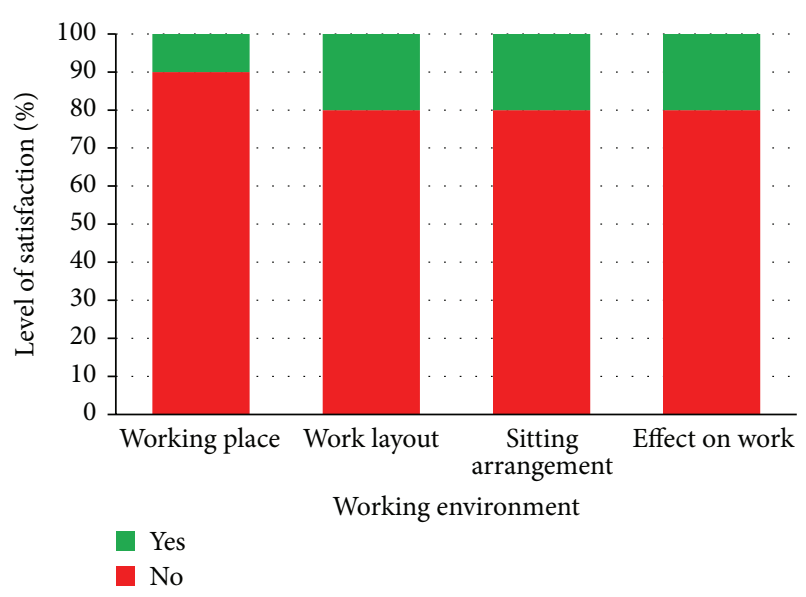

FIGURE 4: Presenting the percentage level of satisfaction of existing workers with the working environment.

(7) The location of centralized mill monitoring system, P.A. system, and indicators were not accurate.

\section{Results and Discussion}

2.1. Ergonomic Assessment of the Pulpit Workers. The survey data obtained from the existing workstation, workers, and workers' body posture were assessed and analysed using the student version of ErgoFellow software. This software has many tools to analyse the different aspects of workers and their work environment from ergonomic point of view. This study uses seven relevant ergonomic tools, namely, RULA (rapid upper limb assessment), REBA (rapid entire body assessment), OWAS (Ovako working posture analyzing system), Suzzane Rodgers, Moore and Garg (strain index), quick exposure check (QEC), and Lehmann, to carry out the ergonomic analysis with the present data. This software was also used for checking the feasibility of the proposed working methods, workstation, body parts movements, and so forth in the light of existing one to get the best results.

2.1.1. RULA (Rapid Upper Limb Assessment). Rapid upper limb assessment (RULA) is an important ergonomic tool 


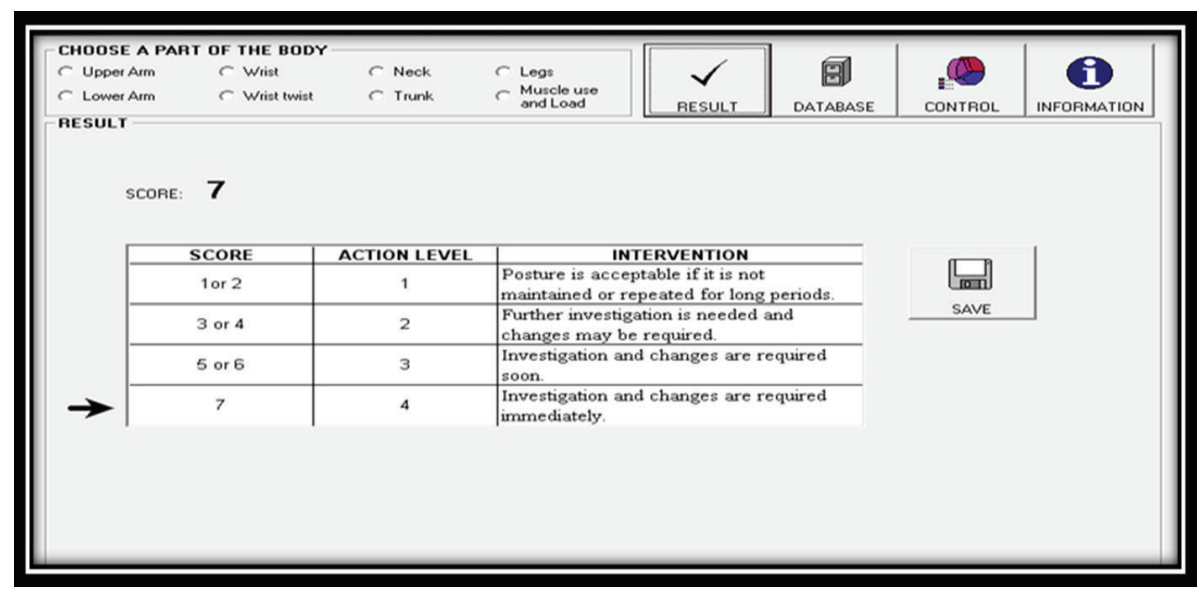

FIGURE 5: Presenting the final outcome of RULA of seven operators working at the pulpit.

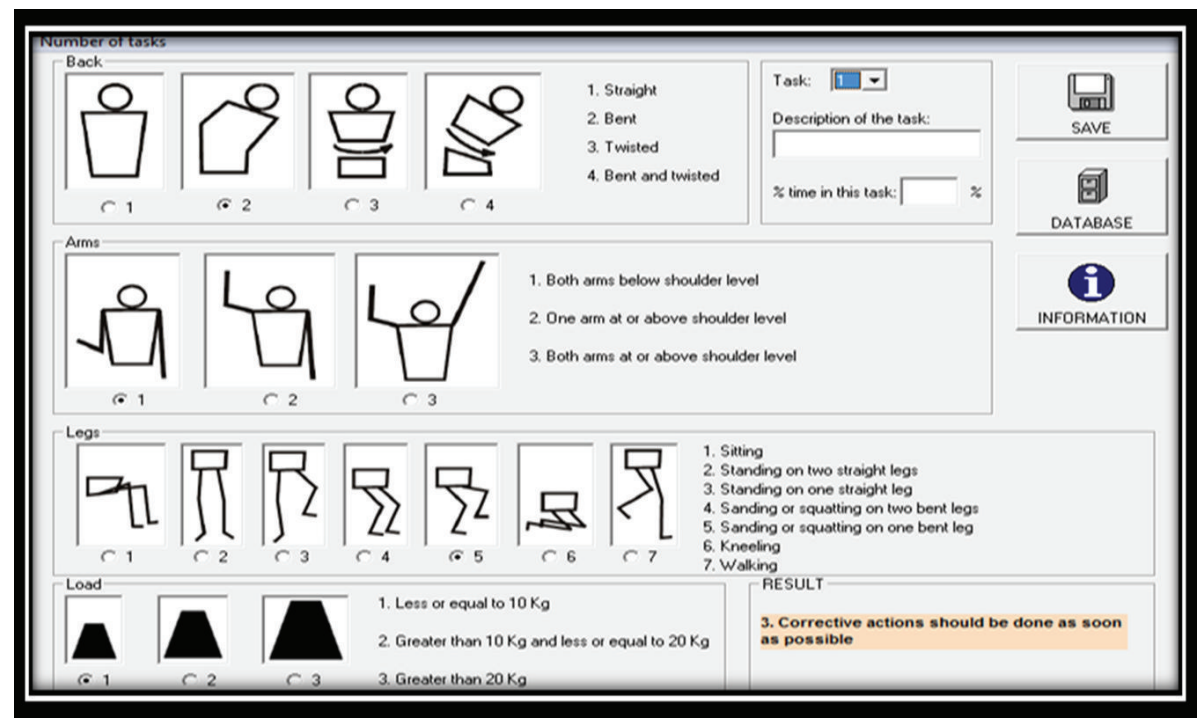

FIGURE 6: Presenting the final outcome of REBA of seven operators working at the pulpit.

widely used for investigating the exposure of individual workers to risk factors associated with work-related upper limb disorders $[11,12,14]$. The RULA is a very quick and important survey method for ergonomic investigations of workers [14]. The data concerning the body posture of seven operators in Table 1 were used in RULA. The final results of the software analysis are presented in Figure 5. It may be seen in Figure 5 that the existing work postures of seven workers are hazardous. Therefore, further investigations and changes in the body postures of the workers are needed immediately.

2.1.2. REBA (Rapid Entire Body Assessment). Rapid entire body assessment (REBA) is another important ergonomic assessment tool which uses a systematic process to evaluate whole body postural MSDs and risks associated with the tasks $[12,14]$. For instance, it is used to evaluate required or selected body posture, forceful exertions, type of movement or action, repetition, and coupling.

The REBA was used in assessing the ergonomic analysis of the entire bodies of seven operators using the survey data from Table 2. The result in Figure 6 indicates that the work postures under study are hazardous. Thus it necessitates the changes in whole body posture of the seven workers.

2.1.3. OWAS (Ovako Working Posture Analysing System). The OWAS (Ovako working posture analysing system) is an ergonomic method for evaluating the postural load during the work $[12,14]$. The OWAS is based on a simple classification of work postures. This method allows one to estimate the degree of a worker's static load at a workstation by analyzing the body posture. Using the survey data in Table 2, the OWAS analysis was carried out and the final result is presented in Figure 7. The results in Figure 7 point out that the body postures of all seven operators are risky; thus the corrective actions should be taken as soon as possible.

2.1.4. Suzzane Rodgers. This ergonomic tool is also available in ErgoFellow. One of the features of this tool is that it shows the result in colour. For example, red is the sign of very high priority for change. Similarly, purple, yellow, and green 


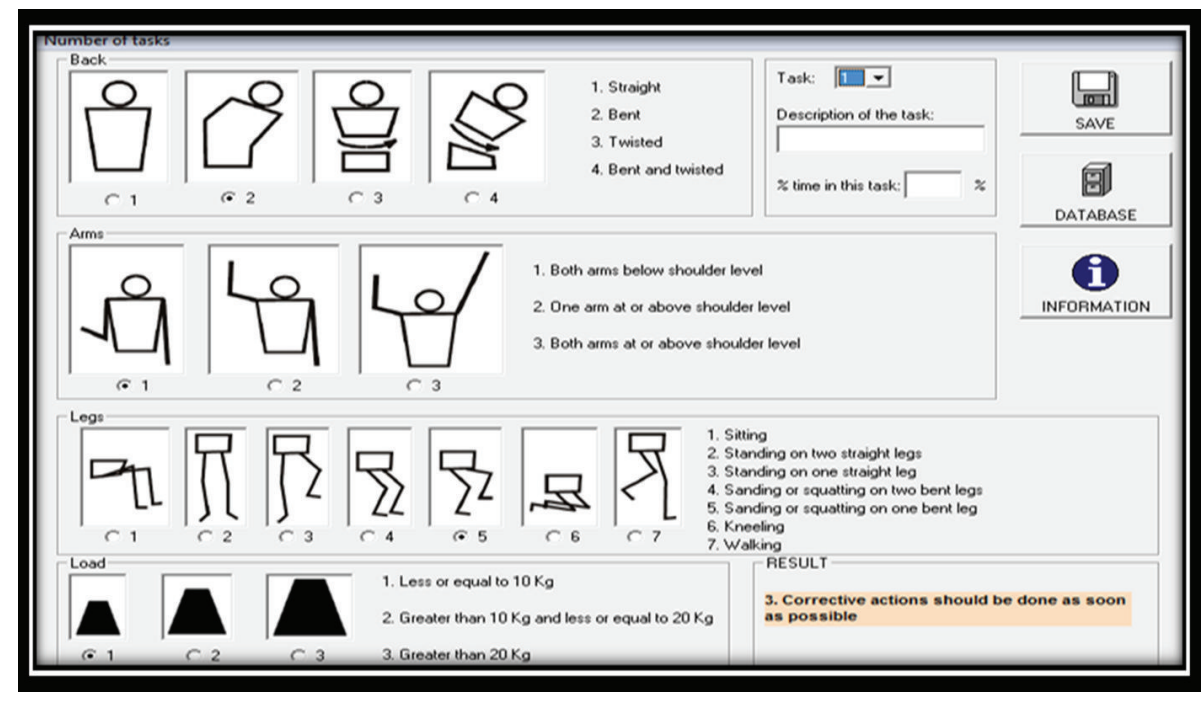

FIgURE 7: Presenting the final outcome of OWAS of seven operators working at the pulpit.

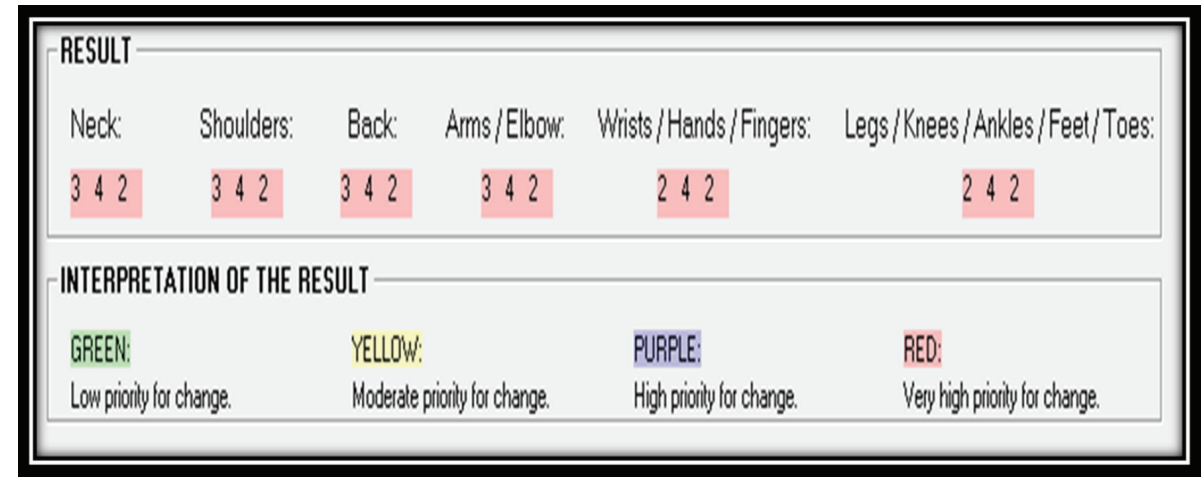

FIGURE 8: Showing the final outcome of Suzzane Rodgers of seven operators working at the pulpit.

are the signs of high priority for change, moderate priority for change, and low priority for change, respectively. Three factors, namely, effort, duration, and frequency of work, were taken into account during use of this ergonomic tool $[12,14]$. The final results are as mentioned in Figure 8. The results clearly indicate the red sign and signify that seven workers are having very high priority for change of work postures.

2.1.5. Moore and Garg (The Strain Index). The strain index which was proposed by Moore and Garg (1995) is also available in the ErgoFellow [15]. This ergonomic tool considers the six job risk factors: intensity of exertion, duration of exertion, efforts per minute, head/wrist posture, speed of work, and duration of task $[12,14]$. At the same time, these six job risk factors are defined on their respective scale to evaluate the work performance. And the product of values corresponding to these six factors is called the strain index. The strain index assessment was carried out on seven workers and the results are displayed in Figure 9. It is concluded from this result that the work postures of seven operators are hazardous. Consequently, the corrective steps are needed to overcome the present situation.
2.1.6. QEC (Quick Exposure Check). The QEC (quick exposure check) tool of the ErgoFellow was also used for assessing musculoskeletal risks of a worker $[12,14,16]$. A distinguishing feature of this tool is that it uses conversations between the observer and the worker. This result shows the good or bad situation within the range of the score. As the score increases, the situation will become worse. Eight factors, namely, back, shoulder/arm, wrist/hand, neck, vibration, driving, workspace, and stress, were given as input. The QEC results of the seven operators are presented in Figure 10 and found that the work postures of seven operators are worse. Thus the corrective measures are needed to overcome the present situation.

2.1.7. Lehmann. This ergonomic tool calculates the metabolism of workers [14]. The position of the body, description of the work, and the work duration are only required for the calculation. Notably, these three requirements are the same for all seven operators since they are working at the same pulpit. The ErgoFellow based calculation shows in Figure 11 that the average energy consumption was found to be $725 \mathrm{Kcal}$ for each of the seven operators in sitting position. But this 


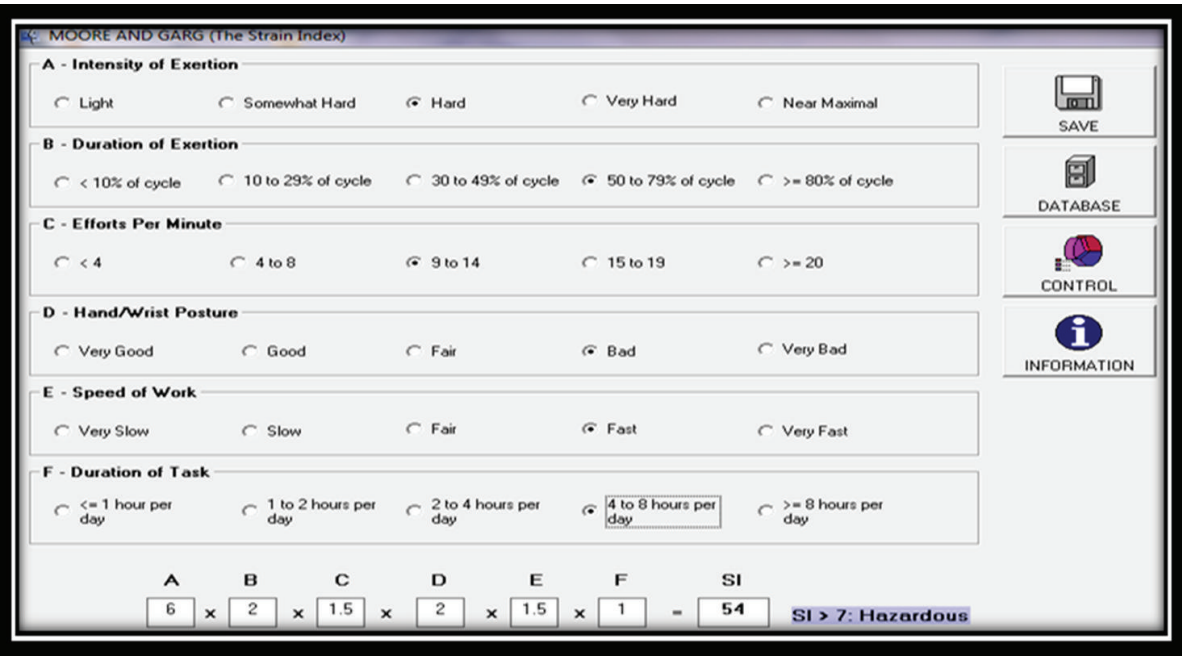

FIGURE 9: Presenting the final outcome of Moore and Garg of seven operators working at the pulpit.

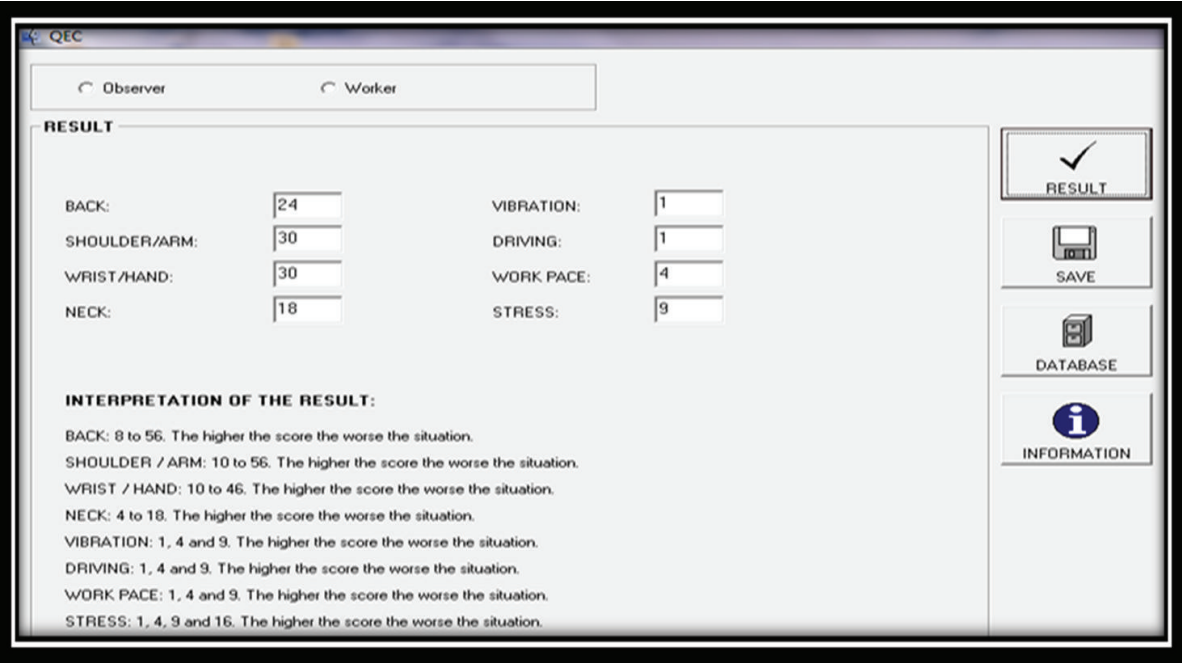

FIGURE 10: Presenting the final outcome of QEC of seven operators working at the pulpit.

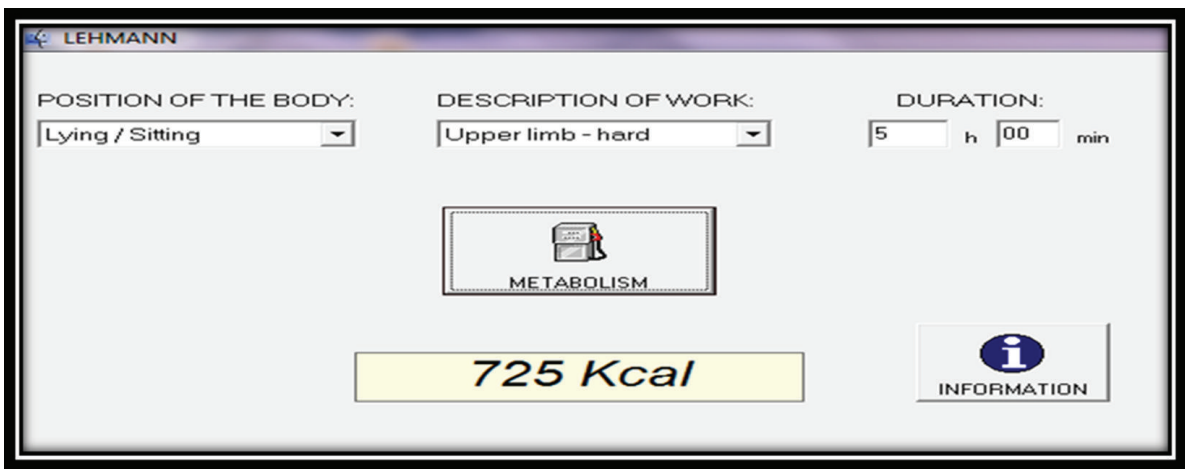

FIGURE 11: Presenting the final outcome of Lehmann of seven operators working at the pulpit. 
TABLE 3: Final outcomes of seven ErgoFellow tools used in the present study.

\begin{tabular}{|c|c|c|c|c|}
\hline Activity & Tool & Score & Risk level & Action \\
\hline \multirow{6}{*}{$\begin{array}{l}\text { Feeding of billets into the } \\
\text { reheating furnace by operator }\end{array}$} & RULA & 7 & 4 (high) & $\begin{array}{l}\text { Investigation and changes are } \\
\text { required immediately }\end{array}$ \\
\hline & REBA & 10 & 4 (high) & $\begin{array}{l}\text { High risk, investigating and } \\
\text { implementing change }\end{array}$ \\
\hline & OWAS & - & High & $\begin{array}{l}\text { Corrective action should be done } \\
\text { as soon as possible }\end{array}$ \\
\hline & Suzzane Rodgers & - & High & Very high priority for change \\
\hline & Moore and Garg (strain index) & 7 & 4 (high) & Hazardous \\
\hline & QEC (quick exposure check) & - & High & Worse situation \\
\hline \multicolumn{5}{|c|}{ Lehmann } \\
\hline Position of the body & Description of work & & tion & Metabolism \\
\hline Sitting & Upper limb-hard & & & $725 \mathrm{kcal}$ \\
\hline
\end{tabular}

TABLE 4: A comparison of different parameters of the existing and the modified pulpit.

\begin{tabular}{|c|c|c|}
\hline Parameters & Existing layout & Ergonomically designed proposed layout \\
\hline Control panel & $\begin{array}{l}\text { Span and height of control panel were } 1.47 \\
\text { (left side + right side) and } 1 \text { meters with } \\
\text { control levers }\end{array}$ & $\begin{array}{l}\text { Logical arrangement of displays and joystick } \\
\text { type controls and the span and height of } \\
\text { control panel are } 1 \text { and } 0.80 \text { meters }\end{array}$ \\
\hline Chair & $\begin{array}{l}\text { The chair was wooden made with the height } \\
\text { of } 1.70 \text { meters }\end{array}$ & $\begin{array}{l}\text { An ergonomically designed comfortable } \\
\text { adjustable chair with the height of } 1.2 \text { meters }\end{array}$ \\
\hline Elbow height of the operator & 1.20 meters & 0.70 meters \\
\hline Camera & $\begin{array}{l}\text { One camera for viewing reheating furnace } \\
\text { only }\end{array}$ & Two cameras for clear viewing of both sides \\
\hline Communication system & Not clearly audible & $\begin{array}{l}\text { A good communication system with } \\
\text { extendable microphone }\end{array}$ \\
\hline Visibility & Not clearly visible because of opaque glasses & Improved visibility with transparent glasses \\
\hline Signal system & Two light bulbs with different colours & Two light signals with alarm have been placed \\
\hline
\end{tabular}

energy consumption is quite high; therefore, remedial actions are needed to minimize the metabolism problem of these workers.

The summary of the seven ergonomic tools used in the analysis is presented in Table 3. It is now quite easier to assess if the risk level is high or critical and also to conclude the type of corrections needed. For instance, the RULA and REBA reveal that risk is high; therefore, corrective steps are needed. It is to be noted that the ergonomic survey amongst all the seven operators had the same problems; therefore, outcomes of seven ergonomic evaluation tools were the same. Further, the outcomes were calculated for the entire duration while working.

2.2. The Proposed Modified Workstation Design. After identifying the MSDs amongst seven operators, we have proposed a modified workstation or pulpit design. Table 4 compares the different parameters of the existing and modified pulpit. The important components of the pulpit are control panel, chair, elbow height of operator, camera, communication system, visibility system, and signal systems. In order to improve the working condition and efficiency of the operators, the following modifications are suggested upon considering Table 4.
(1) The old control panel is to be replaced by a new control panel with a logical arrangement of displays and controls.

(2) An ergonomically designed comfortable adjustable chair suitable for prolonged working in sitting posture is to be provided to the operator.

(3) A camera has been proposed for clear viewing of Roll tables 1, 2, and 3 which will help in minimizing billets overlapping during actual feeding to reheating furnace via Roll table from charging table.

(4) A good communication system with extendable microphone is proposed.

(5) The sound level, temperature, light, and visibility in the pulpit may be suitably upgraded for clear viewing of both sides (charging table and reheating furnace) and made comfortable.

(6) The control levers are replaced by joystick to comfortably operate.

(7) Two light signals with alarm have been placed in the control panel for receiving the signals from charging table side and ejector ram post. 


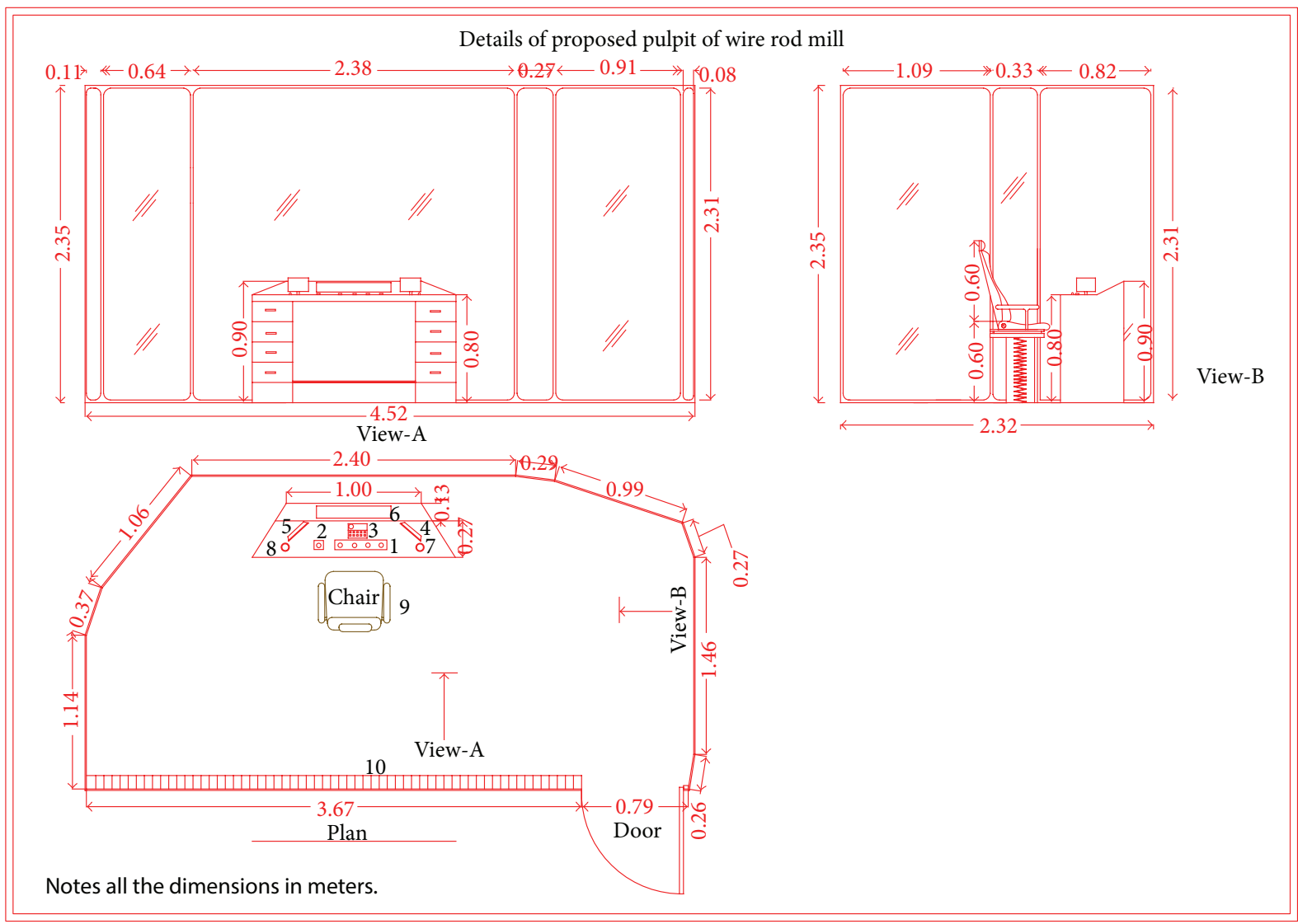
(1) Control switches
(2) Forward pusher switch
(3) Communication system
(4) Display monitor of proposed camera for clear viewing of roll tables 2 and 3
(5) Display monitor of camera for viewing the reheating furnace

(6) Centralised mill monitoring system

(7) Light signal from charging table

(8) Light signal from ram post

(9) Ergonomically designed chair

(10) A.C. duct

FIGURE 12: Showing the details of the proposed layout of the pulpit: (1) control switches, (2) forward pusher switch, (3) communication system, (4) display monitor of proposed camera, (5) display monitor of camera, (6) centralised mill monitoring system, (7) light signal from charging table, (8) light signal from ram post, (9) ergonomically designed chair, (10) A.C. duct, and (11) bench.

(8) The centralized mill monitoring system has to be placed in the control panel.

(9) Established proper functioning of the existing air cooling duct is proposed.

Availability of clear instructions for operation, maintenance, and safety with provision of first aid box and firefighting equipment inside the pulpit is suggested. With increasing production targets and the high speed operation of the mill, it was felt that pulpit needs to be modified for enhancing the mill productivity. A schematic sketch of the modified pulpit is also presented in Figure 12 and shows that there is major change of control panel and workspace if one compares the existing pulpit shown in Figure 2.

Finally, Table 5 presents a comparison of seven ergonomic tools used before and after the modification of the pulpit design. The comparison of all seven ergonomic tools reveals that the risk levels of seven workers are under control after the modification of the existing pulpit.

In addition to the above corrective steps, ergonomically designed chair will ensure the proper work posture and enhance the working efficiency of operators and this will minimize the chances of MSDs in the operators. Single and small control desk for all operations will reduce the span of work for each operator. This will also facilitate operation and improved workstation design. A joystick type of control will enable the operator to be in comfortable sitting position, looking straight while billet feeding operation is going on. This will also eliminate the unnecessary body movement of the operators executed in the existing design of control levers. Finally, an important suggestion to practitioners is that one should try to use maximum number of ergonomic tools depending on ergonomic problems and related data as this will give better insight of the ergonomic issues. 


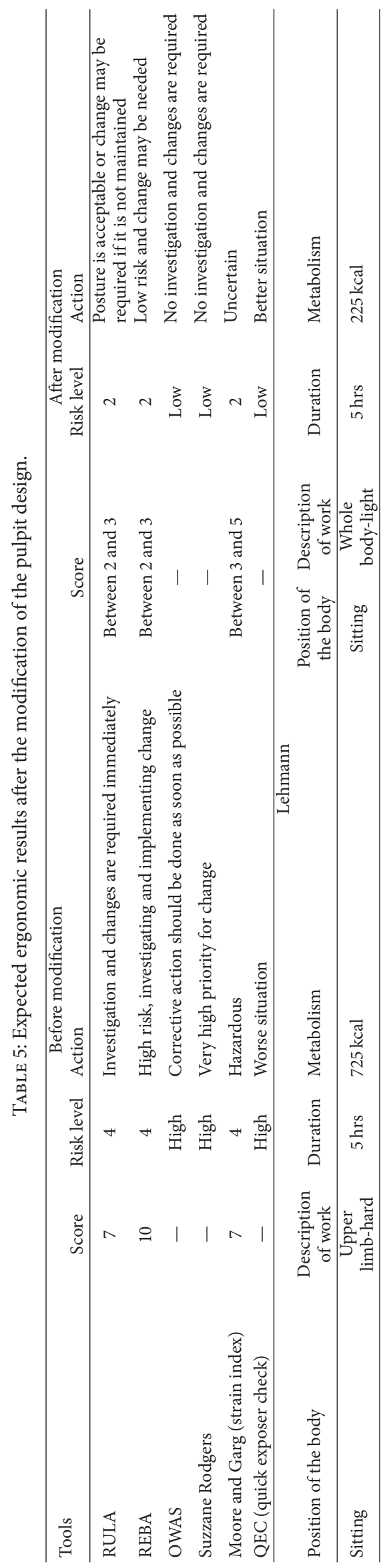




\section{Conclusions}

Observational methods and ergonomic tools have enabled us to identify poor postures of the workers at the pulpit. Ergonomic tools RULA, REBA, OWAS, QEC, Moore and Garg, Suzzane Rodgers, and Lehmann are found to be effective for assessing the MSDs problems amongst the workers and modifying the design of the pulpit. Further, suggestions are also made for improving the working conditions surrounding the pulpit. As a result, the MSDs problems can now be minimized by adopting the proposed methods of working as well as the ergonomically improved pulpit design. It is expected that workers can now perform better with fewer MSDs at the modified pulpit.

\section{Conflict of Interests}

The authors declare that there is no conflict of interests regarding the publication of this paper.

\section{References}

[1] S. Niu, "Ergonomics and occupational safety and health: an ILO perspective," Applied Ergonomics, vol. 41, no. 6, pp. 744-753, 2010.

[2] B. Das and A. K. Sengupta, "Industrial workstation design: a systematic ergonomics approach," Applied Ergonomics, vol. 27, no. 3, pp. 157-163, 1996.

[3] R. H. Westgaard and J. Winkel, "Ergonomic intervention research for improved musculoskeletal health: a critical review," International Journal of Industrial Ergonomics, vol. 20, no. 6, pp. 463-500, 1997.

[4] L. Duncan, Ergonomics and the Management of Musculoskeletal Disorders, Elsevier, New York, NY, USA, 2nd edition, 1997.

[5] W. Karwowski and W. S. Marras, Occupational Ergonomics Design and Management of Work Systems Principles and Applications in Engineering, CRC Press, Boca Raton, Fla, USA, 1999.

[6] T. Ghosh, B. Das, and S. Gangopadhyay, "Work-related musculoskeletal disorder: an occupational disorder of the goldsmiths in India," Indian Journal of Community Medicine, vol. 35, no. 2, pp. 321-325, 2010.

[7] P. H. P. Yeow and R. N. Sen, "Quality, productivity, occupational health and safety and cost effectiveness of ergonomic improvements in the test workstations of an electronic factory," International Journal of Industrial Ergonomics, vol. 32, no. 3, pp. 147-163, 2003.

[8] S. Ouellet and N. Vézina, "Work training and MSDs prevention: contribution of ergonomics," International Journal of Industrial Ergonomics, vol. 44, no. 1, pp. 24-31, 2014.

[9] L. F. M. Kuijt-Evers, F. Krause, and P. Vink, "Aspects to improve cabin comfort of wheel loaders and excavators according to operators," Applied Ergonomics, vol. 34, no. 3, pp. 265-271, 2003.

[10] D. Denis, M. St-Vincent, D. Imbeau, C. Jetté, and I. Nastasia, "Intervention practices in musculoskeletal disorder prevention: a critical literature review," Applied Ergonomics, vol. 39, no. 1, pp. 1-14, 2008.

[11] L. McAtamney and E. N. Corlett, "RULA: a survey method for the investigation of work-related upper limb disorders," Applied Ergonomics, vol. 24, no. 2, pp. 91-99, 1993.

[12] M.-È. Chiasson, D. Imbeau, K. Aubry, and A. Delisle, "Comparing the results of eight methods used to evaluate risk factors associated with musculoskeletal disorders," International Journal of Industrial Ergonomics, vol. 42, no. 5, pp. 478-488, 2012.

[13] C. P. Dewangan, Ergonomic assessment, evaluation, and design of puplit-1 of wire rod mill [M.S. thesis], Visvesvaraya National Institute of Technology, Nagpur, India, 2014.

[14] D. Roman-Liu, "Comparison of concepts in easy-to-use methods for MSD risk assessment," Applied Ergonomics, vol. 45, no. 3, pp. 420-427, 2014.

[15] J. S. Moore and A. Garg, "The strain index: a proposed method to analyze jobs for risk of distal upper extremity disorders," American Industrial Hygiene Association Journal, vol. 56, no. 5, pp. 443-458, 1995.

[16] G. David, V. Woods, G. Li, and P. Buckle, "The development of the Quick Exposure Check (QEC) for assessing exposure to risk factors for work-related musculoskeletal disorders," Applied Ergonomics, vol. 39, no. 1, pp. 57-69, 2008. 

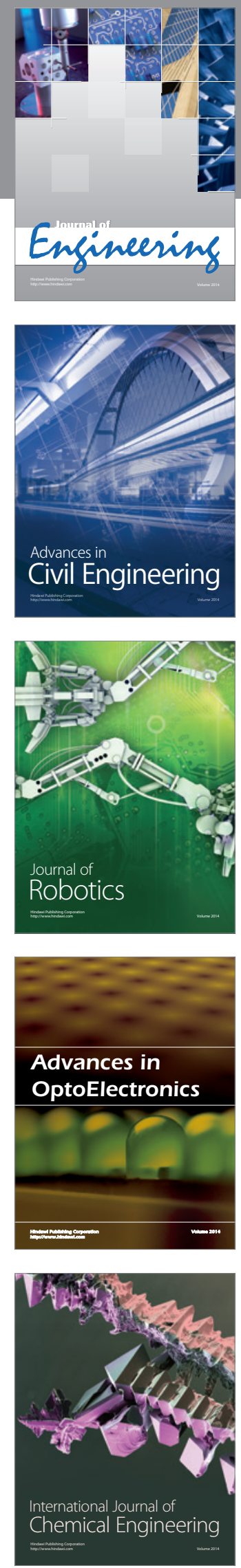

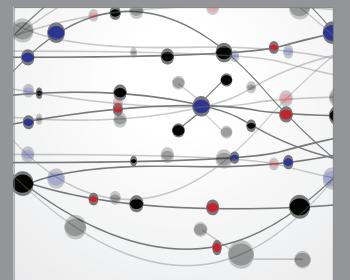

The Scientific World Journal
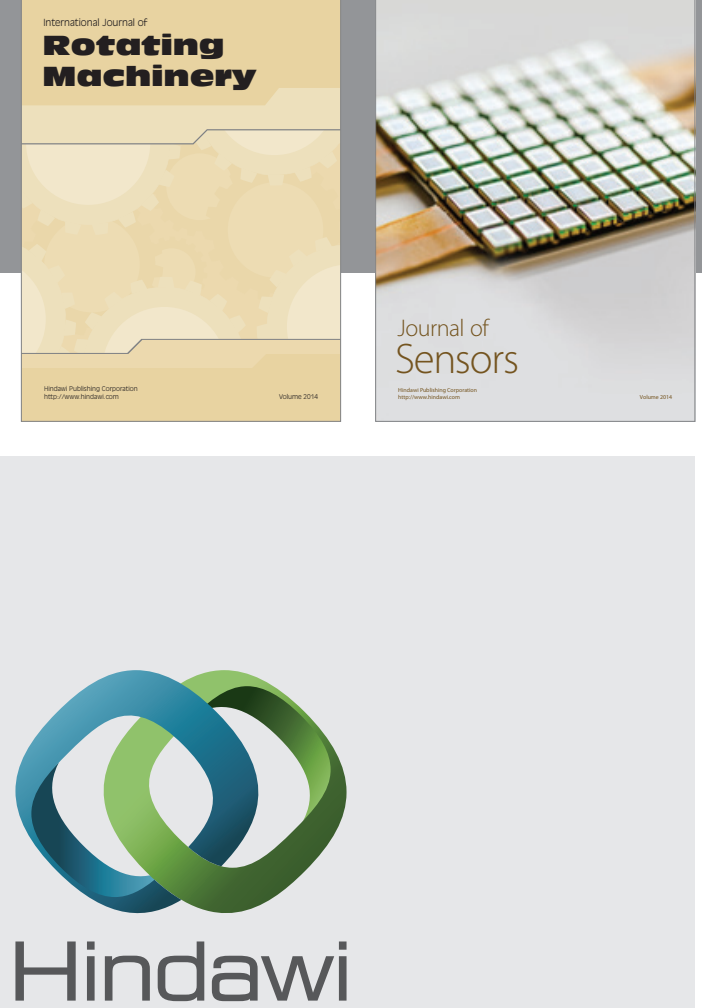

Submit your manuscripts at http://www.hindawi.com
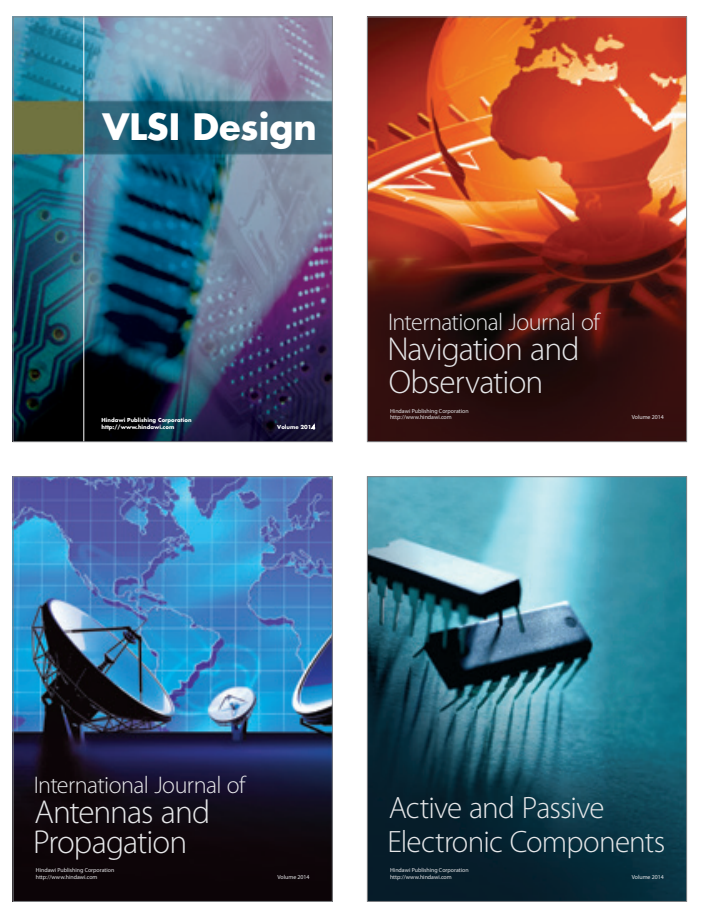
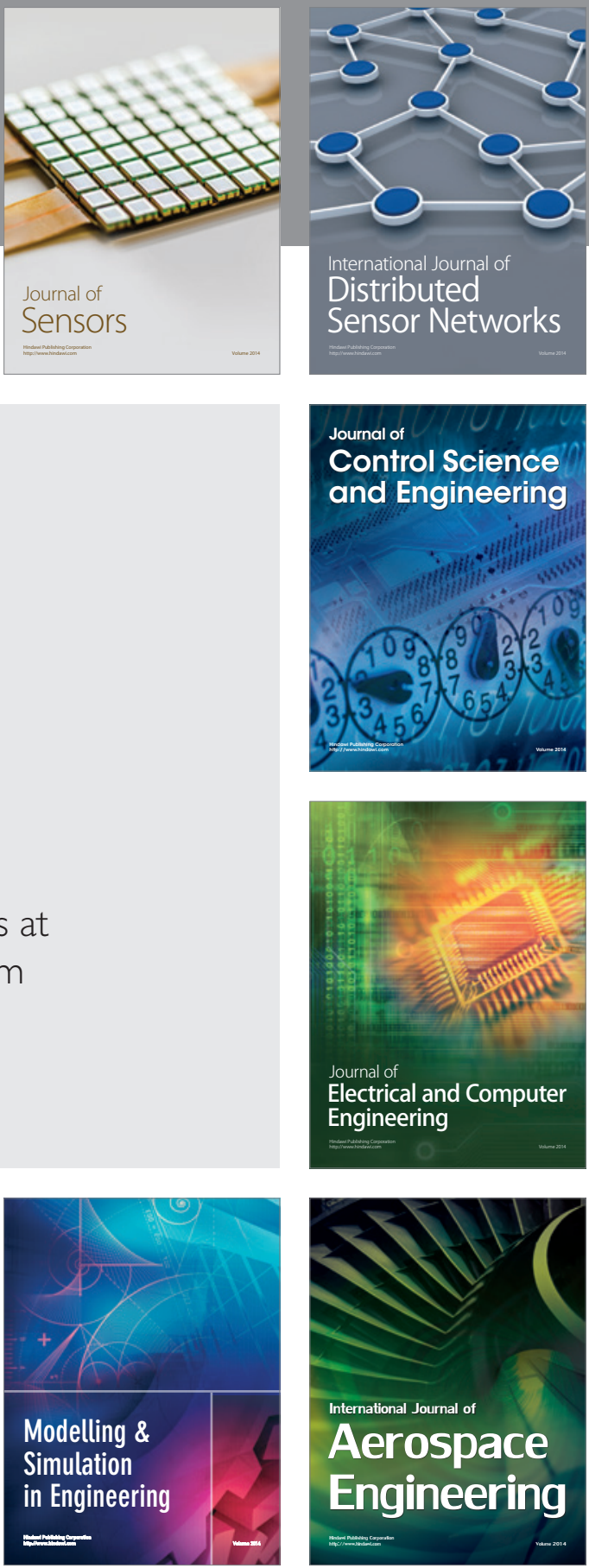

Journal of

Control Science

and Engineering
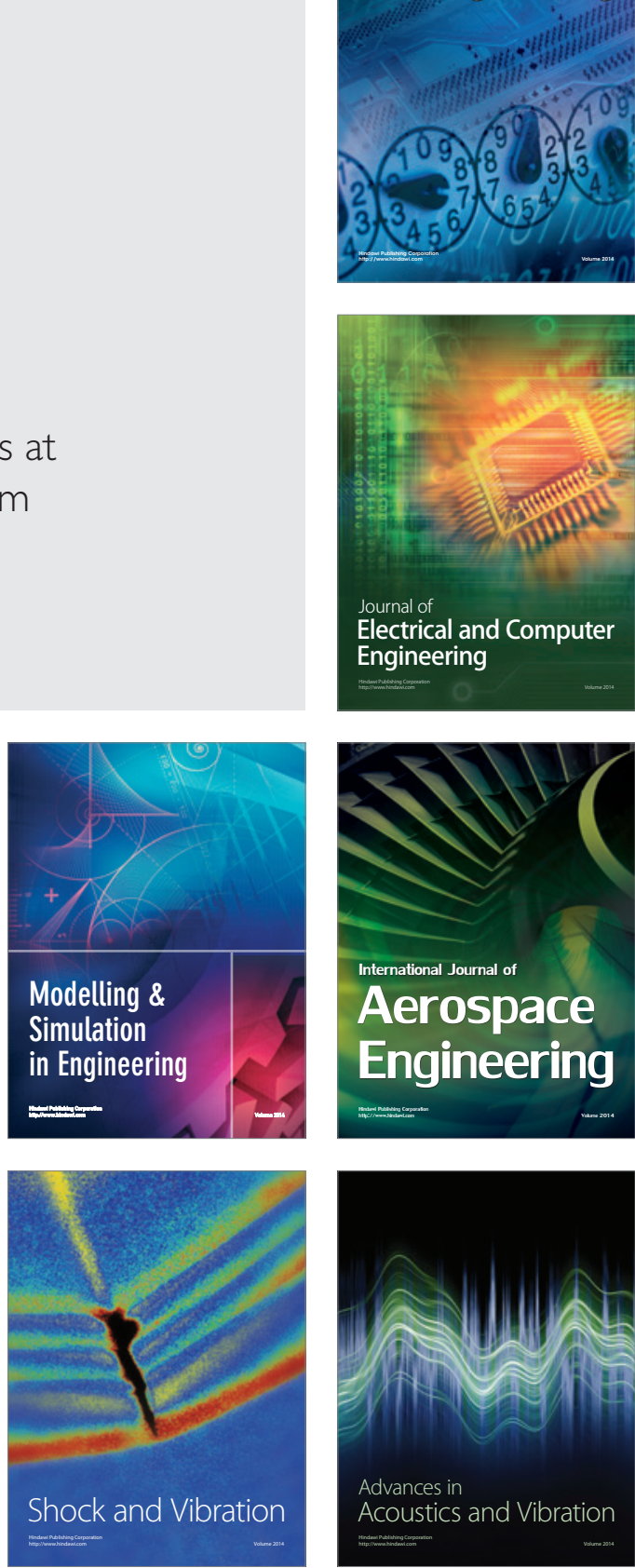